\title{
Organic Polymer Photochemistry
}

\author{
Georges SMETS \\ Laboratory of Macromolecular and Organic Chemistry, \\ K. Universiteit Leuven, B-3030 Leuven, Belgium
}

(Received August 20, 1984)

\begin{abstract}
Some fundamental characteristics of polymer photochemical reactions are shown and their differences with reactions of their model compounds are underlined. Successively are considered: i) photodegradation of methacrylic copolymers carrying photolabile acyl- $O$ $\alpha$ ketooxime side groups and degradation of polyethylenimines by $\mathrm{H}$-abstraction by photoexcited benzophenone; ii) photoinitiation of block polymerization by photolysis of methylbenzoin ether incorporated in a condensation polymer and by selective photolysis of a heterofunctional initiator, e.g., oligoazoperoxides, and azo-di-t-butyl peresters. The advantages of the photochemical initiation with respect to corresponding thermal processes reside in its high selectivity and low reaction temperature; iii) photochemical electron donor-acceptor (EDA) interactions in copolymers of vinylbenzophenone (VB) and p-dimethylaminostyrene (DAS), and in terpolymers VB-DAS and methacrylic esters. The influence of crossed dyad concentration on absorption and emission spectra is underlined. Electron paramagnetic resonance (EPR)-measurements of radial concentration indicate a strong effect of the physical state of the matrix.
\end{abstract}

KEY WORDS Photochemical Reactions / Degradation / Block Polymerization / EDA-Complexation /

It is the purpose of the present paper to illustrate on the basis of recent experimental data some fundamental characteristics of polymer photochemical reactions and their differences with respect to the reactions of their low molecular model compounds. Successively we will consider:

1. photodegradation of polymers carrying photolabile side groups, and photodegradation of polymers in presence of photosensitive compounds

2. photoinitiation of block polymerization using functionalized prepolymers

3. photochemical interactions and photocrosslinking of copolymers of electron donor and electron acceptor monomers.

\section{POLYMER PHOTODEGRADATION}

Two systems will be considered which differ fundamentally by their respective reaction mechanism. The first is based on the photolysis of acyl$O-\alpha$-keto-oxime side groups in a methacrylic copolymer, the second involves $\mathrm{H}$-abstraction by photoexcited benzophenone of polyethylenimines. a) Photochemical initiation of chain degradation has gained interest for microlithography purposes and ultraviolet resist materials. Degradation may be continued with depolymerization if the formation of active centra occurs above the ceiling temperature of the system. High quantum yield of degradation requires the incorporation of photolabile groups, which accelerate the main chain scission. Such requirement is fully realized by $\alpha$-keto- $O$-acyl oximes of which the quantum yield of photolysis $\phi_{\mathrm{s}}$ is equal to 0.84 in benzene and 1.4 in carbon tetrachloride as shown by Delzenne et al. ${ }^{1}$ The reaction scheme is

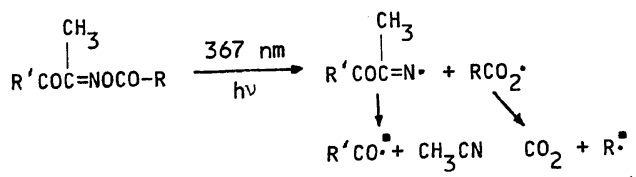

It is assumed that the $\mathrm{n}-\pi^{*}$ absorption of the $\mathrm{C}=\mathrm{N}$ group is followed by scission of the $\mathrm{N}-\mathrm{O}$ band of the oxime, generating two radicals. Delzenne $e t$ al. showed also that copolymers of methyl methacrylate 
and 2,3-butanedione-2-oximino methacrylate can act as photochemical macroinitiator for the graft polymerization of styrene and acrylamides, and that in absence of monomer, they degrade progressively as shown by the decrease of their solution viscosity. On the other hand, Chandross et al. ${ }^{2}$ have shown the use of copolymers of methyl methacrylate and acyloximino methacrylate ester as deep UV resists and found it about 5 times faster than poly(methyl methacrylate) (PMMA) at $\lambda>240 \mathrm{~nm}$. Thus 1phenyl-1,2-propanedione-2- $O$-methacroyloxime (OMA-Ph; $\mathrm{R}^{\prime}=\mathrm{C}_{6} \mathrm{H}_{5}, \lambda_{\text {max }}: 338 \mathrm{~nm}, \varepsilon=90$ ) and 2.3 butanedione-2- $O$-methacroyloxime (OMA-Me; $\mathrm{R}^{\prime}=\mathrm{CH}_{3}, \lambda_{\text {max }}: 320 \mathrm{~nm}, \varepsilon=20$ ) have been prepared and copolymerized with methyl methacrylate (1 to $20 \mathrm{~mol} \%$ oxime). ${ }^{3}$ The photoinitiated degradation was carried out in benzene solution $\left(5 \mathrm{~g} \mathrm{dl}^{-1}\right)$ using an irradiation wavelength of $367 \mathrm{~nm}$.

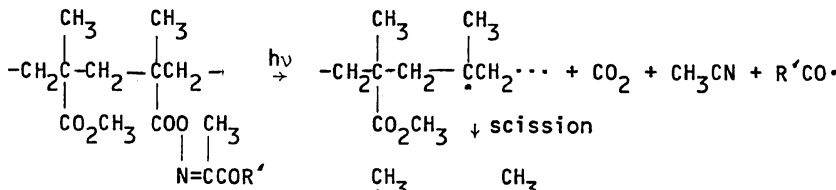

$$
\begin{aligned}
& -\left.\mathrm{CH}_{2}\right|_{\mathrm{CO}_{2} \cdot \mathrm{CH}_{3}} ^{\mathrm{CH}_{3}}+\prod_{\mathrm{CH}_{2}=\mathrm{CCH}_{2}}^{\mathrm{CH}_{3}} \cdots
\end{aligned}
$$

Acetonitrile and the endgroup $\begin{gathered}-\mathrm{CH}_{2}-\mathrm{C}=\mathrm{CH}_{2} \\ \mathrm{CH}_{3}\end{gathered}$

were easily identified by ${ }^{1} \mathrm{H}$ NMR and carbon dioxide by infrared spectrometry

Eventually the radical $\mathrm{R}^{\prime} \mathrm{CO}$ - or $\mathrm{R}^{\prime}$ - may abstract a $\mathrm{H}$-atom and originate another chain scission

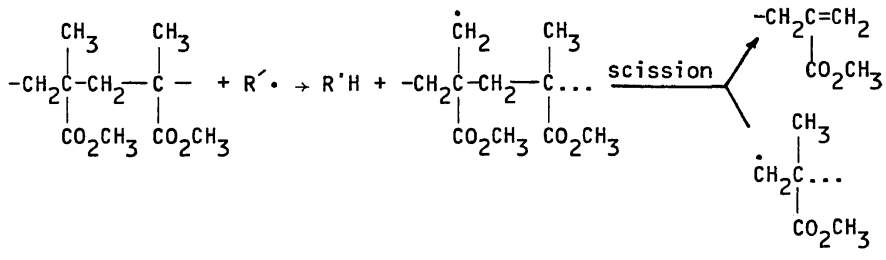

or may induce the decomposition of another $O$ oximino-ester, increasing the quantum yield $\phi_{\mathrm{s}}$<smiles>[R]O/C(C)=N/[13C](=O)[O-]</smiles>

Degradation was followed by gel-permeation chromatography (Figure 1) and the number of chain scissions per molecule calculated from the equation $N_{\mathrm{s}}=\left(M_{n_{0}} / M_{n_{t}}\right)-1, M_{n_{0}}$ and $M_{n_{t}}$ being the numberaverage molecular weight before and after irradiation at time $t$. The quantum yield of chain scission $\phi_{\mathrm{s}}$ is expressed by $\phi_{\mathrm{s}}=N_{\mathrm{s}} / I_{\mathrm{a}} t N_{\mathrm{A}}$; on the average it is equal to 0.8 when $R^{\prime}$ is phenyl and only 0.2 when $R^{\prime}$ is methyl. As can be seen from Table I the chain degradation of OMA-Ph copolymers is rapid and practically independent of the irradiation temperature (Figure 2). On the contrary, with

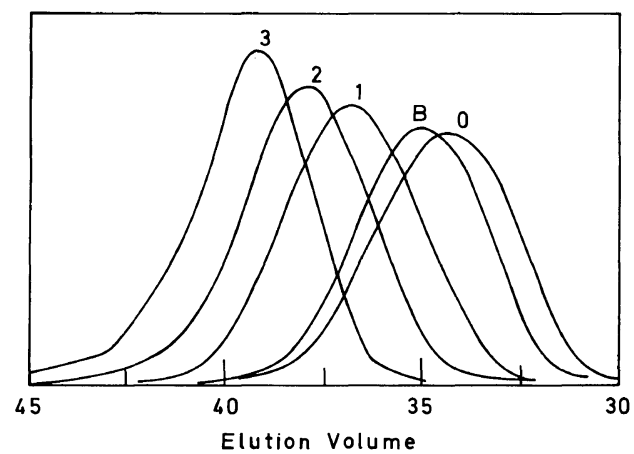

Figure 1. GP-chromatograms of Co(MMA80-OMAPh20). $i_{\text {irr }}, 367 \mathrm{~nm}$. 0, before irradiation; $1,15 \mathrm{~min}$ irradiation; 2, 35 min irradiation; 3, 75 min irradiation; B, PMMA before and after $75 \mathrm{~min}$ irradiation (unchanged).

OMA-Me copolymers the reaction is slow (Table II). In both cases however it is impossible to detect chain scission in solid films at 25 or $60^{\circ} \mathrm{C}, M_{n}$ 
Table I. Photodegradation of co(MMA-OMA-Ph) polymer $\left(\lambda_{\text {irr }}, 367 \mathrm{~nm}\right)$

\begin{tabular}{|c|c|c|c|c|c|c|c|}
\hline \multirow{2}{*}{ Solution $^{a}$} & \multirow{2}{*}{$\begin{array}{c}\mathrm{mol}^{\%} \% \\
\mathrm{OMA}-\mathrm{Ph}\end{array}$} & \multicolumn{2}{|c|}{ Irradiation } & \multirow{2}{*}{$\frac{I_{\mathrm{a}}}{\mathrm{E} \mathrm{cm}^{-2} \mathrm{~s}^{-1}}$} & \multirow{2}{*}{$M_{n}^{\mathrm{b}}$} & \multirow{2}{*}{$N_{\mathrm{s}}^{\mathrm{c}}$} & \multirow{2}{*}{$\phi_{\mathrm{s}}{ }^{\mathrm{d}}$} \\
\hline & & time/min & $t /{ }^{\circ} \mathrm{C}$ & & & & \\
\hline & \multirow[t]{4}{*}{20} & - & 25 & \multirow{4}{*}{$4.7 \times 10^{-9}$} & 28,000 & & \\
\hline & & 15 & & & 9,900 & 1.83 & 0.77 \\
\hline & & 35 & & & 6,100 & 3.60 & 0.65 \\
\hline & & 75 & & & 3,000 & 8.3 & 0.63 \\
\hline & \multirow[t]{4}{*}{5.4} & - & 25 & \multirow[t]{4}{*}{$4.3 \times 10^{-9}$} & 29,100 & & \\
\hline & & 15 & & & 10,500 & 1.77 & 0.79 \\
\hline & & 30 & & & 6,600 & 3.42 & 0.76 \\
\hline & & 60 & & & 4,760 & 5.11 & 0.57 \\
\hline & \multirow[t]{3}{*}{5.4} & - & 60 & $4.2 \times 10^{-9}$ & 29,100 & & \\
\hline & & 15 & & & 10,200 & 1.85 & 0.84 \\
\hline & & 60 & & & 4,100 & 6.14 & 0.70 \\
\hline & \multirow[t]{4}{*}{3} & - & 25 & $3.5 \times 10^{-9}$ & 31,200 & - & \\
\hline & & 15 & & & 13,300 & 1.34 & 0.68 \\
\hline & & 30 & & & 8,600 & 2.63 & 0.67 \\
\hline & & 60 & & & 7,300 & 3.24 & 0.41 \\
\hline \multirow{4}{*}{$\begin{array}{l}\text { Film } \\
+30 \mathrm{wt}^{\circ} \%, T_{\mathrm{g}} 32^{\circ} \\
\text { DBP }\end{array}$} & \multirow{4}{*}{3.5} & & & & & & \\
\hline & & - & 60 & $1.75 \times 10^{-9}$ & 20,900 & & \\
\hline & & 15 & & & 17,500 & 0.19 & \\
\hline & & 30 & & & 6,700 & 2.12 & \\
\hline
\end{tabular}

a In benzene $\left(5 \mathrm{~g} \mathrm{dl}^{-1}\right)$. b Determined by GPC.

c $N_{\mathrm{s}}=\left(M_{n_{\mathrm{o}}} / M_{n_{\mathrm{t}}}\right)-1$. $^{\mathrm{d}} \phi_{\mathrm{s}}$, quantum yield of chain scission.

Table Il. Photodegradation of co(MMA-OMA-Me) polymer $\left(\lambda_{\text {irr }}, 367 \mathrm{~nm}\right)$

\begin{tabular}{|c|c|c|c|c|c|c|c|}
\hline \multirow{2}{*}{$\begin{array}{c}\mathrm{C}_{6} \mathrm{H}_{6} \\
\text { solution }\end{array}$} & \multirow{2}{*}{$\begin{array}{c}\mathrm{mol} \% \\
\text { OMA-Me }\end{array}$} & \multicolumn{2}{|c|}{ Irradiation } & \multirow{2}{*}{$\frac{I_{\mathrm{a}}}{\mathrm{E} \mathrm{cm}^{-2} \mathrm{~s}^{-1}}$} & \multirow{2}{*}{$M_{n}$} & \multirow{2}{*}{$N_{\mathrm{s}}$} & \multirow{2}{*}{$\phi_{\mathrm{s}}$} \\
\hline & & time $/ \mathrm{min}$ & $t /{ }^{\circ} \mathrm{C}$ & & & & \\
\hline & \multirow[t]{4}{*}{2} & - & 25 & $1.6 \times 10^{-9}$ & 22,500 & & \multirow{4}{*}{0.21} \\
\hline & & 15 & & & 22,500 & & \\
\hline & & 30 & & & 19,700 & 0.14 & \\
\hline & & 60 & & & 15,400 & 0.46 & \\
\hline Film & 2 & - & 60 & $0.77 \times 10^{-9}$ & 28,000 & & \\
\hline $30 \mathrm{wt}^{\circ} \%$ & & 5 & & & 29,300 & & \\
\hline \multirow[t]{2}{*}{ DBP } & & 15 & & & 22,000 & 0.27 & \\
\hline & & 30 & & & 21,300 & 0.32 & \\
\hline
\end{tabular}

remaining practically unchanged. It is assumed that free radical recombination in cage prevails on account of lack of diffusion possibilities below $T_{\mathrm{g}}$. Indeed if the films are plasticized by addition of di$n$-butyl phthalate (DBP) in order to lower their $T_{\mathrm{g}}$, degradation again occurs.

This example stresses again the rate determining role of the physical state of the glassy matrix on the chemical degradation phenomena. Usually that influence was investigated in the case of the reversible cis-trans isomerization of photochromic groups (azo- and spicobenzopyran groups ${ }^{4}$; evidently chain segment mobility, i.e., the distribution of the free volume in the polymer matrix must affect the course of most reactions, including degradation phenomena. $^{5}$

b) The second photodegradation example is that of polyethylenimine (PEI) in the presence of benzophenone as photoinitiator. It is generally admitted that photoinduced $\alpha$-hydrogen transfer from 


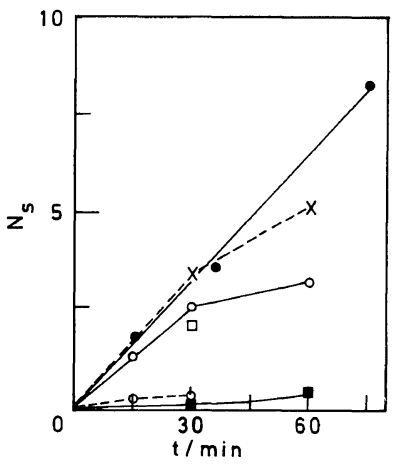

Figure 2. Number of chain scissions. Influence of time of irradiation. Co(MMA-OMA-Ph) $\mathrm{mol} \% \mathrm{O}, 3 ; \times$, 5.4 ;, 20 in benzene solution $\square, 3.5$ in film $+30 \%$ DBP. Co(MMA-OMA-Me) $\mathrm{mol}^{\circ} \%$ :, 2 in benzene solution; $\mathrm{O}, 2$ in film $+30 \% \mathrm{DBP}$. the amine to the triplet excited benzophenone occurs with intermediate formation of a pair of ion radicals. ${ }^{6}$ Semipinacol radicals $\mathrm{Ar}_{2} \mathrm{COH}$ are formed, which mainly dimerize to benzpinacol, while the polymeric radicals undergo $\beta$-scission with chain degradation.

Cross-termination processes by disproportionation or addition between the primary radicals as well as reaction of a macro-radical with benzophenone also involve photoreduction of benzophenone however without chain degradation. Therefore from the reaction scheme given below it must be expected that the rate of benzophenone photoreduction will exceed the rate of chain scission.

$$
\begin{aligned}
& \operatorname{Ar}_{2} C=0 \\
& \downarrow \text { hv } \\
& -\left(\mathrm{NHCH}_{2} \mathrm{CH}_{2}-\right)_{n}+\left(\mathrm{Ar}_{2} \mathrm{C}=0\right)^{*} \rightarrow-\left(\mathrm{NHCH}_{2} \mathrm{CH}_{2}-\right)_{n}^{+}\left(\mathrm{Ar}_{2} \mathrm{C}=0\right)-\overline{\mathrm{H} \text {-transfer }} \\
& \ldots \mathrm{NHCH}_{2} \mathrm{CH}_{2} \operatorname{NH}^{\mathrm{NH} \mathrm{CHCH}_{2}} \mathfrak{N H C H}_{2} \mathrm{CH}_{2} \ldots+\mathrm{Ar}_{2} \dot{\mathrm{C}}-\mathrm{OH} \\
& + \text { chain scission } \\
& \text { (a) } \ldots \mathrm{NHCH}_{2} \dot{\mathrm{CH}}_{2}+\mathrm{NH}=\mathrm{CHCH}_{2} \mathrm{NHCH}_{2} \mathrm{CH}_{2} \ldots \\
& \text { (b) } \ldots \mathrm{NHCH}_{2} \mathrm{CH}_{2} \mathrm{NHCH}=\mathrm{CH}_{2}+\mathrm{NHCH}_{2} \mathrm{CH}_{2} \ldots
\end{aligned}
$$

termination

$$
\begin{aligned}
& 2 \mathrm{Ar}_{2} \dot{\mathrm{C}}-\mathrm{OH} \rightarrow \mathrm{Ar}_{2} \mathrm{C}(\mathrm{OH}) \mathrm{C}(\mathrm{OH}) \mathrm{Ar}_{2} \\
& \mathrm{Ar}_{2} \dot{\mathrm{C}}-\mathrm{OH}+\ldots \mathrm{NHCH}_{2} \mathrm{CH}_{2} \mathrm{NH}^{\dot{\mathrm{CHCH}}} \mathrm{NHCH}_{2} \ldots \rightarrow \mathrm{Ar}_{2} \mathrm{CHOH}+\ldots \mathrm{NHCH}_{2} \mathrm{CH}_{2} \mathrm{NHCH}=\mathrm{CHNHCH}_{2} \ldots \\
& \text {... }\left.\mathrm{NHCH}_{2} \mathrm{CH}_{2}\right|_{\mathrm{C}(\mathrm{OH}) \mathrm{Ar}_{2}} \mathrm{NHCH}_{2} \mathrm{NHCH}_{2} \cdots
\end{aligned}
$$

H-transfer

$\mathrm{Ar}_{2} \mathrm{C}=\mathrm{O}+\ldots \mathrm{NHCH}_{2} \mathrm{CH}_{2} \mathrm{NHCHNH} \ldots+\mathrm{Ar}_{2} \mathrm{COH}+\ldots \mathrm{NHCH}_{2} \mathrm{CH}_{2} \mathrm{NHCH}=\mathrm{CHNH}-$

In the present experiments all irradiations were carried out in a Rayonet photochemical reactor at constant temperature under inert atmosphere. Both reactions, photoreduction of benzophenone and chain degradation have been followed respectively by ultraviolet spectrophotometry and solution viscosimetry. ${ }^{7}$ By following the decrease of absorbance at $336 \mathrm{~nm}$ with the time of irradiation, the rate of photoreduction of benzophenone can easily be mea- sured; it is proportional to the concentration of PEI and the phenone concentration (Figure 3). Noteworthy is that this rate is almost equivalent for linear - $\mathrm{NH}-\mathrm{CH}_{2}-\mathrm{CH}_{2}-$ and branched PEI, which contains only $40 \%$ secondary amino groups (of which 25 belong to the main chain and $15 \%$ in side chains), besides $30 \%$ primary and $30 \%$ tertiary groups according to the following structure. ${ }^{7-9}$ 
Table III. Photoreduction of benzophenone with aliphatic amines ${ }^{\mathrm{a}}$

\begin{tabular}{|c|c|c|c|}
\hline \multirow{2}{*}{ Amine } & $-\Delta\left(\mathrm{Ar}_{2} \mathrm{CO}\right) / \Delta t$ & \multirow{2}{*}{$\begin{array}{c}\text { Rate per } \\
\begin{array}{c}\alpha-\mathrm{H} \text {-atom } / \mathrm{min} \\
\times 10^{4}\end{array}\end{array}$} & \multirow{2}{*}{$\begin{array}{c}\text { Relative } \\
\text { rate }\end{array}$} \\
\hline & $\mathrm{moll}^{-1} \min ^{-1} \times 10^{3}$ & & \\
\hline $\mathrm{N}\left(\mathrm{CH}_{2} \mathrm{CH}_{3}\right)_{3}$ & 5.8 & 9.7 & 1 \\
\hline $\mathrm{NH}\left(\mathrm{CH}_{2} \mathrm{CH}_{3}\right)_{2}$ & 3.2 & 8 & 0.83 \\
\hline $\mathrm{NH}_{2} \mathrm{CH}_{2} \mathrm{CH}_{2} \mathrm{CH}_{3}$ & 0.9 & 4.5 & 0.44 \\
\hline
\end{tabular}

${ }^{a}[$ amine $]=0.107 \mathrm{moll}^{-1} .\left[\mathrm{Ar}_{2} \mathrm{CO}\right]=4.39 \times 10^{-3} \mathrm{moll}^{-1} . t, 30^{\circ} \mathrm{C}$. Solvent dimethyl sulfoxide-water $\left(99: 1, \operatorname{vol}^{\circ}\right)$.

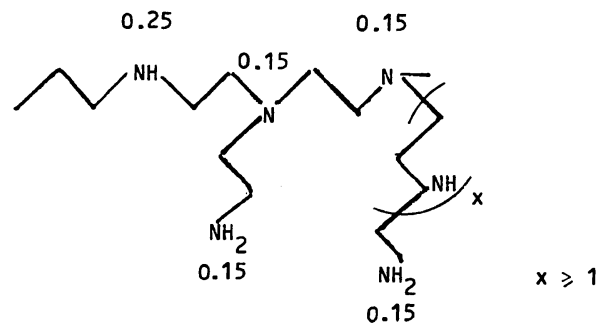

Structure of b-PEI

Photoreduction experiments in the same experimental conditions as for PEI with propylamine, diand tri-ethylamine as model compounds, give the results given in Table III; they show the decreasing order tertiary $>$ secondary $>$ primary amine.

At a same amine concentration, the photoreduction of benzophenone was found ten times faster with diethylamine than with the linear PEI. So far this difference is not explained satisfactorily.

Chain degradation after hydrogen transfer was followed by measuring the change of inherent viscosity of the PEI solution with the time of irradiation. (The irradiation was carried out in a Rayonet photochemical reactor at constant temperature under nitrogen atmosphere.) The concentration of benzophenone was 2.14 or $4.28 \times 10^{-3}$ mol $1^{-1}$, that of PEI ranged from 0.1 to 0.5 molar. By plotting the number of chain scissions per molecule $\left(N_{\mathrm{s}}=\eta_{0} / \eta-1\right)$ against the time, $\eta_{0}$ and $\eta$ being the inherent viscosity before and after irradiation at time $t$, one obtains the rate of degradation $S$, i.e., the number of chain scission per time unit (Figure 4). As can be seen from Figure $5 S$ depends linearly on the polymer concentration; by extrapolating at infinite dilution (Figure 5) $S_{0}$ values are obtained. The data are summarized in Table IV. Though the values are difficult to compare with those of benzophenone reduction, nevertheless Table IV shows that the number of chain scission

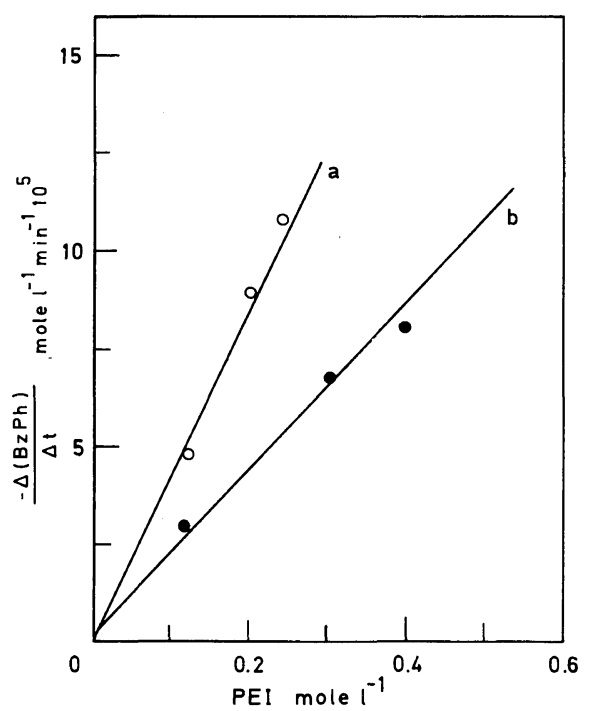

Figure 3. Rate of benzophenone $(\mathrm{BzPh})$ photoreduction. Influence of the concentrations of b-PEI $\left(M_{n}=\right.$ $40,000)$ and benzophenone. $t, 40^{\circ} \mathrm{C}$; $[\mathrm{BzPh}]$ in $\mathrm{mol} \mathrm{l}^{-1}$ : (a) $4.28 \times 10^{-3}$; (b) $2.14 \times 10^{-3}$; solvent, dimethyl sulfoxide (DMSO).

per minute is about one-third for linear PEI compared to the branched one, while the photoreduction rate is equivalent. This difference becomes even more pronounced if one considers that only the amino group in the main chain can contribute to chain scission, i.e., $45 \%$ of the total amount.

This second example shows that a comparison polymer/model compound can only be significant if the detailed internal structure of the polymer is known.

\section{PHOTOINITIATION OF BLOCK POLYMERIZATION}

Block polymers can be prepared photochemically 


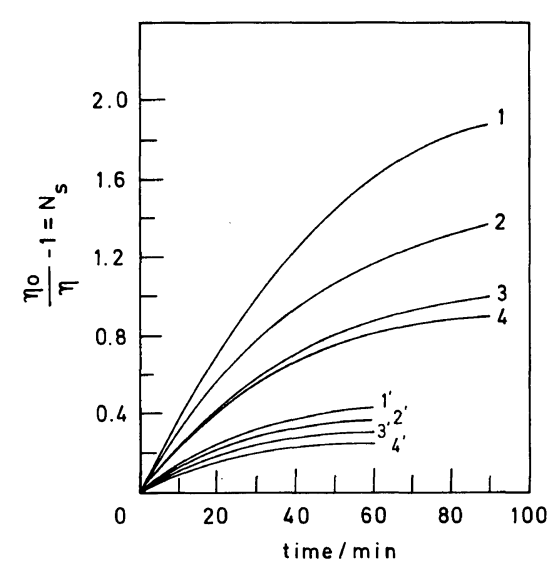

Figure 4. Variation of number of scissions per molecule with time of irradiation: solvent, $\mathrm{DMSO} / 40^{\circ} \mathrm{C}$; [BzPh], $2.14 \times 10^{-3} \mathrm{~mol} \mathrm{l}^{-1}$. [PEI] in mol $\mathrm{l}^{-1}$ : branched (1) 0.116 ; (2) 0.166 ; (3) 0.299 ; (4) 0.399 ; linear (1') 0.235 ; (2') $0.353 ;\left(3^{\prime}\right) 0.465 ;\left(4^{\prime}\right) 0.577$.

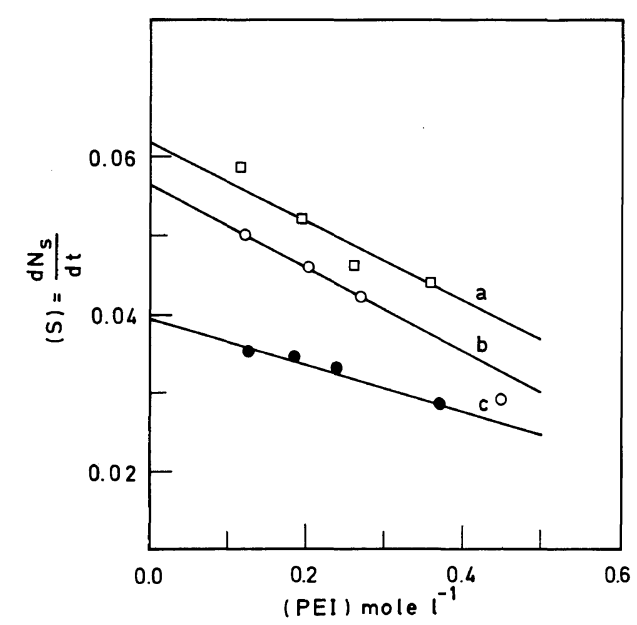

Figure 5. Rate of chain scission. Dependence on b-PEI concentration. [BzPh], $4.28 \times 10^{-3} \mathrm{~mol}^{-1} \cdot t /{ }^{\circ} \mathrm{C}$, (a) 50 ; (b) 40 ; (c) 30 .

Table IV. Rate of degradation $S_{0} \times 10^{2}$ (Influence of the temperature and structure of the polymer)

\begin{tabular}{ccc}
\hline$T /{ }^{\circ} \mathrm{C}$ & Linear PEI & Branched PEI \\
\hline 30 & 1.2 & 4.0 \\
40 & 2 & 5.7 \\
50 & 2.2 & 6.2 \\
\hline$E_{\mathrm{a}}$ in kJ mol & & $15.5 \pm 1$ \\
\hline
\end{tabular}

by photolysis of light sensitive groups incorporated in a condensation polymer in the presence of a vinyl monomer; their formation results from the second step by free radical polymerization of the monomer. Depending on the mode of termination by disproportionation and/or by addition, their general structure will be PC-PV and/or PC-PV-PC (where $\mathrm{PC}$ indicates a condensation polymer sequence and $\mathrm{PV}-\mathrm{a}$ polyvinyl sequence) as far as the polymer contains one photolabile group per macromolecule. If the number of these groups exceeds the unity, the block polymers will also contain PV-PC-PV triblocks, and multiblocks of the $\mathrm{PV}(\mathrm{PC}-\mathrm{PV})_{x}$ and $(\mathrm{PC}-\mathrm{PV})_{x}$ type, as resulting from the middle sequences. This procedure was already applied earlier by Smets et al. ${ }^{11}$ for the synthesis of block copolymers of polytetrachlorobisphenol-A-adipate and polystyrene by incorporating 5 to $15 \mathrm{~mol} \%$ of 1 ( $p$-hydroxyphenyl) 1,2-propanedione-2-oxime into the polyester. The yield of block polymers was very high, only 5$10 \%$ polystyrene being extractable by boiling cyclohexane.

In the present paper the same reaction principle is applied to the incorporation of $p, p^{\prime}$-dihydroxybenzoin methylether (BME) in poly(bisphenol-A carbonate). ${ }^{12}$ BEM itself was prepared by a four step synthesis, of which the two first steps were recently published ${ }^{13}$ : 1) 1-methoxymethylation of p-hydroxy benzaldehyde, 2) benzoin condensation of the protected $p$-hydroxyaldehyde, 3) methylation of the benzoin secondary alcohol, 4) deprotection of the phenolic group (reaction scheme 9). In

$$
\underset{\mathrm{P}-\mathrm{CH}_{3} \mathrm{OCH}_{2} \mathrm{OC}_{6} \mathrm{H}_{4} \mathrm{CHO}}{\stackrel{\mathrm{KCN}}{\mathrm{EtOH}, \mathrm{H}_{2} \mathrm{O}}}
$$$$
\mathrm{pp}-\mathrm{CH}_{3} \mathrm{OCH}_{2} \mathrm{OC}_{6} \mathrm{H}_{4} \mathrm{C}-\underset{1}{\mathrm{CH}} \mathrm{C}_{6} \mathrm{H}_{4} \mathrm{OCH}_{2} \mathrm{OCH}_{3}
$$

$$
\begin{aligned}
& \text { 1. } \mathrm{CH}_{3} \mathrm{I}+\mathrm{Ag}_{2} \mathrm{O} \\
& \text { p p } \mathrm{HOC}_{6} \mathrm{H}_{4}-\underset{\|}{\mathrm{C}}-\mathrm{CH}_{6} \mathrm{C}_{4} \mathrm{H}_{4} \mathrm{OH} \text { BME } \\
& 0 \mathrm{OCH}_{3}
\end{aligned}
$$


Table V. Photolysis of BME poly(bisphenol-A carbonate) ${ }^{\mathbf{a}}$

\begin{tabular}{|c|c|c|c|c|c|c|}
\hline \multicolumn{2}{|c|}{$[\eta]_{20 \mathrm{C}}$ in $\mathrm{CHCl}_{3}$} & \multicolumn{2}{|c|}{$M_{n}$} & \multirow{3}{*}{$N_{\mathrm{s}}$} & \multicolumn{2}{|c|}{$\mathrm{BME}$ in $\mathrm{PC}$} \\
\hline & & \multirow{2}{*}{$M_{\mathrm{o}}$} & \multirow{2}{*}{$M_{\mathrm{i}}$} & & \multirow{2}{*}{$\begin{array}{l}\mathrm{BME} / \mathrm{Bis} \mathrm{A} \\
\text { molar ratio }\end{array}$} & \multirow{2}{*}{$\begin{array}{l}\text { Number per } \\
\text { macromol. }\end{array}$} \\
\hline$[\eta]_{0}$ & {$[\eta]_{\mathrm{i}}$} & & & & & \\
\hline 0.73 & 0.39 & 33,600 & 14,800 & 1.27 & $1 / 104$ & 1.26 \\
\hline 0.90 & 0.57 & 50,600 & 28,600 & 0.77 & $1 / 235$ & 0.84 \\
\hline
\end{tabular}

a $1 \mathrm{~g}$ polymer $/ 30 \mathrm{ml} \mathrm{CH} \mathrm{Cl}_{2}$.

order to assure the incorporation of the BME within the polycarbonate chain, it must be first transformed via its bis-chloroformate into bis(bisphenol-A) dicarbonic ester by reaction with a large excess of bisphenol-A; it is assumed that the reactivity of the dicarbonic ester is equal to that of bisphenol-A itself. Polycondensation of the reaction with phosgene produces a polycarbonate with incorporated BEM-groups designated as BME-PC polymers (reaction scheme 10 ). Preliminary experi-

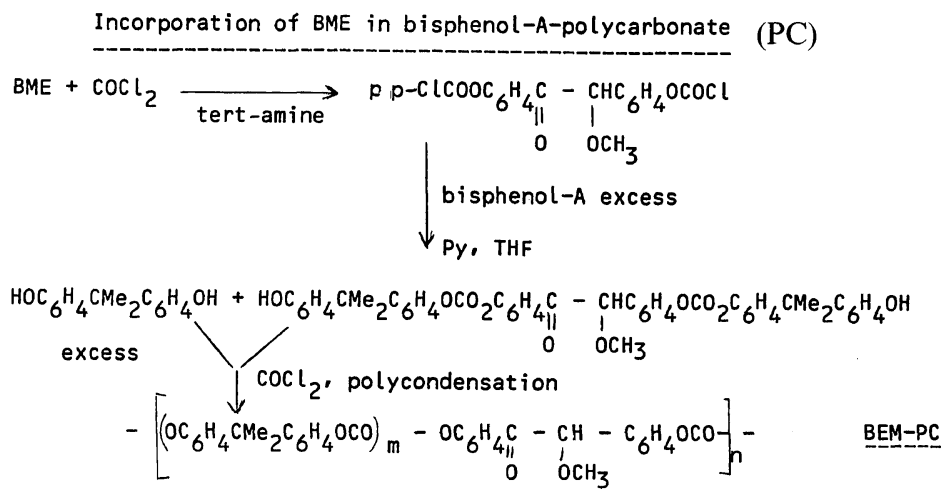

ments had shown that the photolysis of the BMEgroups was completed after one-half hr irradiation, while homopolycarbonate remains unchanged in the same conditions (Figure 6a).

Table $\mathrm{V}$ summarizes the photodecomposition data of two BEM-PC's different in their BEMcontent after irradiation at room temperature $\left(\lambda_{\text {irr }}\right.$ $300 \mathrm{~nm}) .(\eta)_{0}$ and $(\eta)_{\mathrm{i}}$ indicate the intrinsic viscosity of the polymers before and after irradiation; similarly $M_{0}$ and $M_{\mathrm{i}}$ are the number average molecular weights before and after irradiation, as determined by gel permeation chromatography. The molar BME-content of the polymers was determined by proton-NMR analysis. The agreement between the number of chain scissions per macromolecule, $\left(N_{\mathrm{s}}=M_{0} / M-1\right)$ and the BME-content is very remarkable.
When such BME-PC is photolyzed in the same irradiation conditions but in presence of methyl methacrylate, it gives rise to the formation of polycarbonate-PMMA block polymers. The PMAweight fraction remains constant after $1 \mathrm{~h}$ irradiation (Figure 6b); it increases proportionally with the monomer concentration in the dichloromethane solution (Figure 7). Table VI summarizes the experimental data.

The reaction products were almost pure block polymers. Indeed starting from a $33 \mathrm{~mol}^{\circ}$ PCreaction product, extraction with boiling aceton $(30 \mathrm{~h})$ gives only 10 to $11 \%$ weight soluble fraction, which contained $5 \mathrm{~mol} \% \mathrm{PC}$. The composition of the acetone insoluble product was almost unchanged. As expected these block polymers show on differential scanning calorimetry two distinct glass 


\section{G. SMETS}

Table VI. Polymerization of MMA photoinitiated with BME-PC

\begin{tabular}{|c|c|c|c|c|c|c|c|c|c|c|}
\hline \multirow{3}{*}{$\frac{\text { BME-PC }}{\mathrm{g}}$} & \multirow{3}{*}{$\begin{array}{c}\text { BME } \\
\text { concn } \\
\text { moll }^{-1}\end{array}$} & \multicolumn{3}{|c|}{ Feed } & \multirow{3}{*}{$\frac{\begin{array}{c}\text { Total } \\
\text { amount }\end{array}}{\mathrm{g}}$} & \multicolumn{5}{|c|}{ Product. } \\
\hline & & \multicolumn{2}{|c|}{ MMA } & \multirow{2}{*}{$\frac{\mathrm{CH}_{2} \mathrm{Cl}_{2}}{\mathrm{ml}}$} & & \multirow{2}{*}{$\frac{\begin{array}{c}\mathrm{PMA}^{\mathrm{a}} \\
\text { content }\end{array}}{\mathrm{mol}_{\mathrm{o}}}$} & \multirow{2}{*}{$\begin{array}{c}\begin{array}{c}\text { MMA } \\
\text { conversion }\end{array} \\
\%\end{array}$} & \multirow{2}{*}{$\frac{\begin{array}{c}{[\eta]_{20} \mathrm{C}} \\
\text { in } \mathrm{CHCl}_{3}\end{array}}{\mathrm{dl} \mathrm{g}^{-1}}$} & \multirow{2}{*}{$M_{n}^{\mathrm{b}}$} & \multirow{2}{*}{$\frac{\text { Calcd }^{\mathrm{c}}}{\mathrm{MW}}$} \\
\hline & & $\mathrm{mol}$ & $\mathrm{ml}$ & & & & & & & \\
\hline 1.0 & 0.0013 & 0.094 & 10 & 20 & 1.51 & 57 & 6 & 0.45 & 27,200 & 22,500 \\
\hline 1.0 & 0.0013 & 0.14 & 15 & 15 & 1.88 & 67 & 6 & 0.52 & 32,000 & 26,600 \\
\hline
\end{tabular}

Polymerization condition: H.P.-Hg Lamp $>300 \mathrm{~nm}$ for $1 \mathrm{~h}$ at $25^{\circ} \mathrm{C}$.

a Calculated from NMR.

b By GPC calibrated for polystyrene.

c Calculated from NMR results, assuming a diblock PC-PV structure.

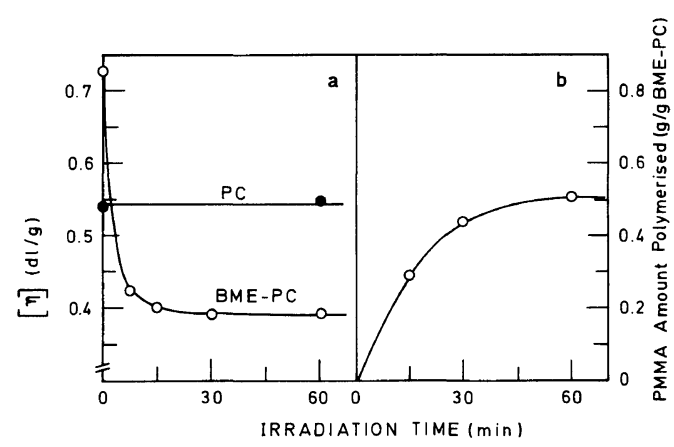

Figure 6. Photolysis of BME-polycarbonate. a) in absence of monomer. Curve PC represents the blank exp. without BEM group. b) in the presence of methyl methacrylate.

methacrylate.

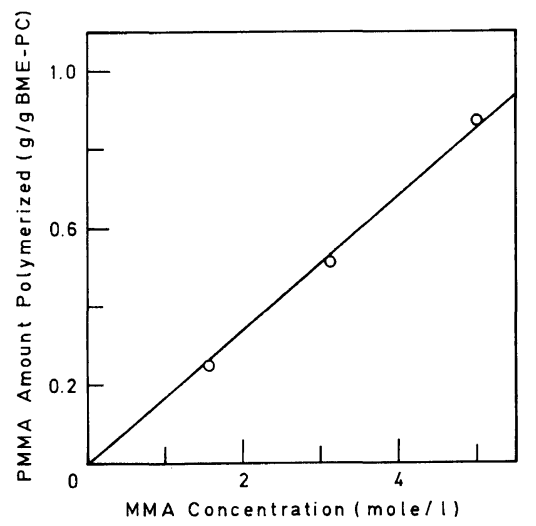

Figure 7. Polymerization of methyl methacrylate photoinitiated with BME-PC. Dependence on monomer concentration. $t, 25^{\circ} \mathrm{C}$. solvent, dichloromethane. transition domains corresponding to PMMA and to partially crystalline $\mathrm{PC}$ at 90 and $176^{\circ} \mathrm{C}$, respectively. The high efficiency of this photochemical block polymerization was confirmed with many other vinyl monomers and will be reported later. This photochemical method permits a regulation of block lengths, the poly(bisphenol-A carbonate) ones by the BME-content, and the polyvinyl block by the polymerization conditions. Its high efficiency makes this method preferable to the thermal decomposition of incorporated azogroups, as was recently described by Ueda and Nagai in the case of polyamide, where the original chain lengths are modified by recombination of radicals and the initiation efficiency towards styrene was as low as $15 \%{ }^{14}$

In this first example of block polymerization, the basic principle of the synthesis was the incorporation of a photolabile group within a condensation polymer. If however two different polyvinyl sequences are desired, the photochemical method has to be adapted to this new problem by using an heterofunctional initiator, i.e., an initiator containing two different thermo- or photolabile groups which differ sufficiently in their decomposition activation energy or selective light absorption to permit a two step synthesis.

In our knowledge Ivanchev and coworkers ${ }^{15-19}$ were the first to use oligoperoxides with peroxidic linkages of different stability, e.g., diacylperoxide, $\alpha$-substituted diacylperoxides, peresters etc. Thus by reaction of nonanedioic peracid with 2-bromononanedioyl dichloride, they obtain following oligoperoxide: 


$$
\begin{gathered}
\mathrm{HO}_{2} \mathrm{CO}\left(\mathrm{CH}_{2}\right)_{7} \mathrm{COO}_{2} \mathrm{H}+\mathrm{ClCOCH}\left(\mathrm{CH}_{2}\right)_{6} \mathrm{COCl} \rightarrow-\left[0 \mathrm{OC}\left(\mathrm{CH}_{2}\right){ }_{7} \mathrm{CO}-0-0-\left.\right|_{\mathrm{Br}} ^{\mathrm{COCH}}\left(\mathrm{CH}_{2}\right)_{6}{ }^{\mathrm{COO}]} \times\right. \\
x=10-18
\end{gathered}
$$

Considering that the $\alpha$-bromoperoxide has a decomposition activation energy of $95.7 \mathrm{~kJ} \mathrm{~mol}^{-1}$ and the unsubstituted one of $123.3 \mathrm{~kJ}$, it is assumed that the difference of $27.6 \mathrm{~kJ} \mathrm{~mol}^{-1}$ is sufficient to enable the 2-step synthesis of styrene-methyl methacrylate block polymers. The higher the degree of polymerization $x$ of the oligoperoxide, the higher the yield of block polymer.
An alternative method which does not require this difference of activation energies is based on the selective photochemical decomposition of one of the groups of the heterofunctional initiation, e.g., azonitrile groups incorporated in an azo-oligoperoxide. ${ }^{20}$ Such compound can easily be prepared by reaction of hydrogen peroxide with $4,4^{\prime}$ azobis(4-cyanopentanoic acid chloride):

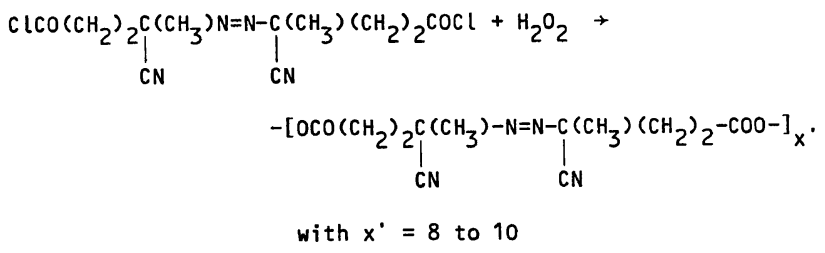

The difference of thermal stability between the azoand peroxidic groups is low; their activation energies of decomposition is $113 \mathrm{~kJ}(27 \mathrm{kcal})$ and $130 \mathrm{~kJ} \mathrm{~mol}^{-1}$ (31 kcal) respectively, and at $70^{\circ} \mathrm{C}$ the azo group decomposes about four times slower than the peroxides. However selective photolysis of the azo groups at 350 or $371 \mathrm{~nm}$ in the presence of styrene permits to obtain a styrene prepolymer containing acyl peroxidic groups. The number of these groups per molecule was evaluated from the ratio $\left(M_{n_{0}} / M_{n_{t}}\right)-1$ where $M_{n_{0}}$ and $M_{n_{t}}$ designate the number average molecular weights before and after thermal decomposition in boiling chlorobenzene; it amounts to 0.64 to 0.87 . This peroxidic polystyrene prepolymer was dissolved in tetrahydrofuran or in trichlorobenzene and used for the free radical polymerization of vinylchloride at $75^{\circ} \mathrm{C}$. After reaction the product mixture was extracted for polystyrene and separated by preparative GPC. Some results are summarized in the following Table VII.

As expected on the basis of the low peroxide content $(0.61-0.64)$ the reaction product contains inert polystyrene. On the other hand homopoly(vinyl chloride) is always formed mainly by chain transfer with the monomer, while the relative importance of transfer with solvent appears from the comparison THF/TCB. Figure 8 shows the GP-chromatograms with infrared detector equip-
Table VII. Block polymerization of peroxidic styrene prepolymer with vinyl chloride ${ }^{a}$

\begin{tabular}{lcc}
\hline & Tetrahydrofuran & Trichlorobenzene \\
\hline$M_{n_{0}}$ & 102,500 & 50,000 \\
$\left(M_{n_{0}} / M_{n_{t}}\right)-1$ & 0.64 & 0.61 \\
VC $/ \mathrm{ml}$ & 80 & 50 \\
Solvent $/ \mathrm{ml}$ & 20 & 35 \\
React. Product & 40 & 54 \\
$\quad$ VC \% & & $31(36,900)$ \\
Polystyrene & $45(66,700)^{\mathrm{c}}$ & $69(39,700)$ \\
PVC+block & $55(42,200)$ & 20 \\
$\quad$ polymer & 18 & 49 \\
PVC & 37 & 33 \\
Block & 25 & \\
Prepolym. in block & &
\end{tabular}

${ }^{a} t, 70^{\circ} \mathrm{C}, 4 \mathrm{~h}$ with $3 \mathrm{~g}$ prepolymer.

b The separation of PVC and block polymer by preparative GPC is uncomplete and reflects also differences in molecular weight instead of chemical composition.

c The values between parentheses indicate number average molecular weight of the polystyrene or of the PVC + block polymer mixture.

ment of the PVC block polymer mixture (after extraction of homopolystyrene with cyclohexane). It can be seen that the polystyrene blocks are more concentrated in the high molecular fractions, while the lowest fractions are homopoly(vinyl chloride), 


\section{G. SMETS}

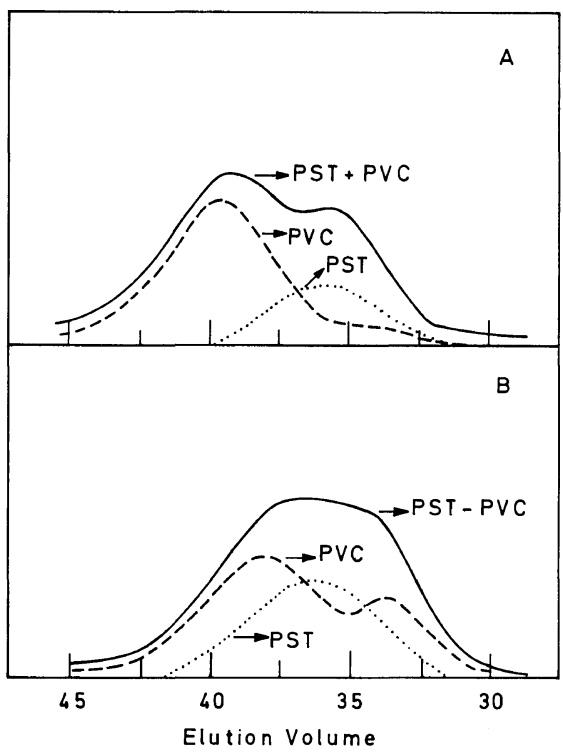

Figure 8. Gel permeation chromatograms with infrared detector of PVC-block polymer mixture prepared in tetrahydrofuran (A) and in trichlorobenzene (B).

and that the polystyrene is more homogeneously distributed in the reaction product obtained in trichlorobenzene.

Similar photochemical essays have been carried out with di-t-butyl 4,4'-azobis(4-cyanoperoxypentanoate) instead of an oligoazoperoxide initiator. This initiator, prepared by reaction of the corresponding bisacid chloride with $t$-butyl hydroperoxide,

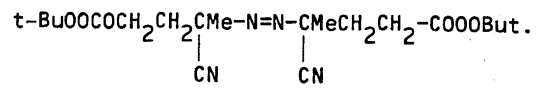

is easily soluble in styrene monomer and can be obtained with a high degree of purity $(>99 \%)$. Photolysis at $367 \mathrm{~nm}$ in the presence of styrene monomers gives a telechelic polystyrene with two perester end groups; its composition determined by ${ }^{13} \mathrm{C}$ NMR corresponds to 2 perester for 242 styrene units, which is in fair agreement with the number average molecular weight 25,600 (246 units) as determined by GPC. This photochemical method for the synthesis of the $\omega, \omega^{\prime}$-bisperoxy-polystyrene has to be prefered to the thermal and redox methods described by Piirma and $\mathrm{Chou}^{21}$ because it offers a well defined and pure polymeric initiator. On heating at $95^{\circ} \mathrm{C}$ in the presence of methyl methacrylate block polymers are obtained in high yield without residual homopolystyrene. In this context mention should be made of the similar bifunctional initiator prepared by Simionescu et al. ${ }^{22}$ carrying two acyl peroxides, e.g., $m$-chlorobenzoylperoxidic groups instead of peresters. So far however no block polymers were described.

\section{PHOTOCHEMICAL INTERACTIONS AND CROSS-LINKING OF EDA-COPOLYMERS}

Interactions between electron donor (D) and electron acceptor (A) groups along a copolymer chain give on photoexcitation excited EDAcomplexes, with ion-radicals pair formation.

$p$-Vinylbenzophenone (VB) and $p$-dimethylaminostyrene (DAS) can easily copolymerize and form EDA-copolymers where the phenone is the electron acceptor (A) and the tertiary amine the electron donor (D). In principle the reaction mechanism is similar to that described above for the photodegradation reaction of polyethyleneimine in the presence of benzophenone. In the present case however excited EDA complexation involves an intramolecular instead of a bimolecular process; moreover the tertiary aryl dimethylamino group is a much better donor group on account of its aromatic substitution. Finally combination of the radicals after $\mathrm{H}$-exchange results in cross-linking. ${ }^{23.24}$

Absorption (at room temperature) and emission (at $77 \mathrm{~K}$ ) spectra of copolymers show a pronounced tendency on complex formation. Mixtures of the two homopolymers PVB and PDAS and mixtures of the model compounds, 4-methylbenzophenone (MBP) and $N, N$-dimethyltoluidine (DMT) do not show intermolecular complex formation. At MBP concentration $10^{-3}$ molar, a high amine concentration (1.5 molar) is needed for observing some red absorption shift. On the contrary copolymers show the existence of a new absorption band, even in high diluted benzene solution $\left(10^{-4}\right.$ molar of both $\mathrm{D}$ and A groups); its optical density increases with increasing DAS-content. On the other hand the intensity of the emission spectra in methyltetrahydrofuran of a co(VB79-DAS21) polymer is much higher than that of PVB in the presence of $10 \mathrm{vol} \%$ dimethylaniline, though the concentration of amines in the copolymers is 1,000 to 10,000 times lower than that of the dimethylaniline (Figure 9). 


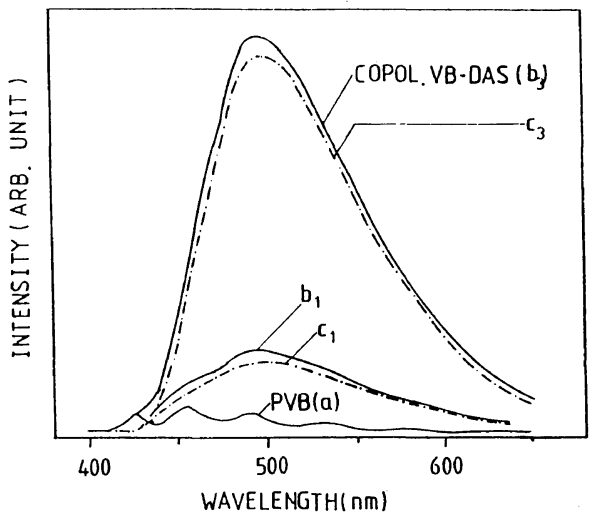

Figure 9. Emission spectra of copolymer (VB79DAS21): $b_{3}$ and difference spectrum: $c_{3}$ and of polyvinylbenzophenone: a, and of polyvinylbenzophenone (PVB) in 1 volume dimethylaniline/9 volume methyltetrahydrofuran. [VB], $4.8 \times 10^{-3} ; t, 77 \mathrm{~K} ; \lambda_{\text {exc }}, 365 \mathrm{~nm}$.

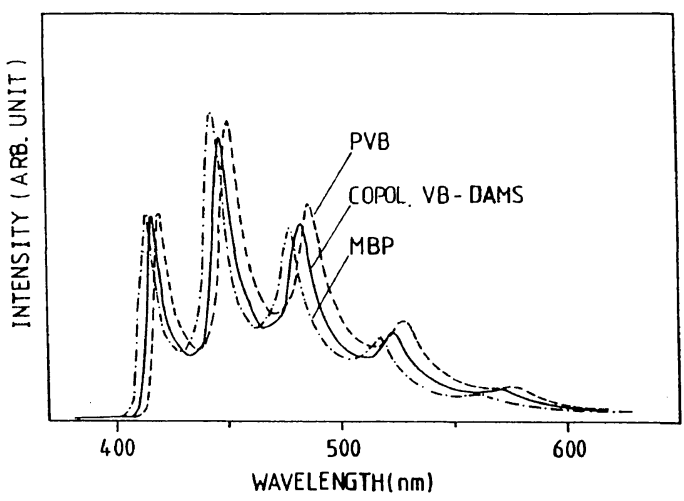

Figure 10. Emission spectra of PVB $\left(4.8 \times 10^{-3}\right)$, methylbenzophenone $\left(1.7 \times 10^{-3}\right)$ and copolymer (VB53-DAMS47) at [VB]: $5.4 \times 10^{-3} t, 77 \mathrm{~K} ; \lambda_{\text {exc }}$, $335 \mathrm{~nm}$; solvent, methyltetrahydrofuran.

It can be shown that the emission spectrum of the copolymer results mainly from the emission of the photoexcited complex. This tremendous difference in phosphorescence intensity between the two systems must be attributed to the high local concentration of both $\mathrm{D}$ and $\mathrm{A}$ groups and particularly the high crossed dyad concentration in the copolymer. In this context it may be interesting to mention that copolymers of $\mathrm{VB}$ and $p$-dimethylaminomethylstyrene $\left(\left(\mathrm{CH}_{3}\right)_{2} \mathrm{NCH}_{2}-\mathrm{C}_{6} \mathrm{H}_{4}-\right.$ $\mathrm{CH}=\mathrm{CH}_{2}$ ) show no clear evidence of complexation between $\mathrm{D}$ and $\mathrm{A}$ units; the emission spectrum of a co(VB53-DAMS47) polymer is similar to

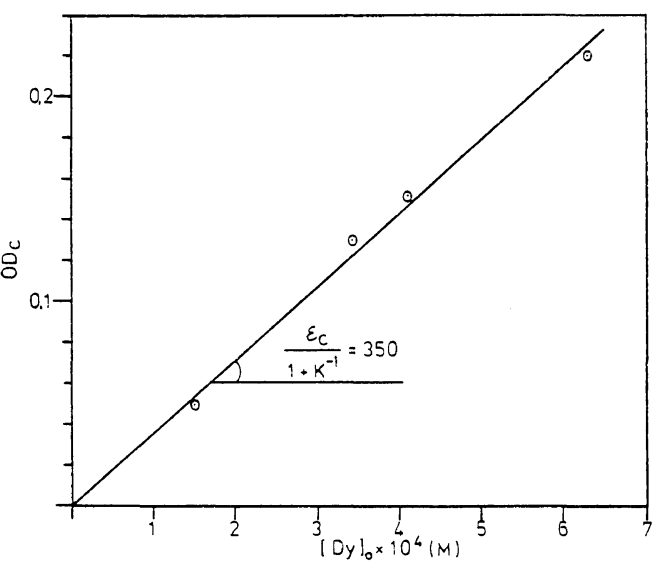

Figure 11. Plot according to dyad complexation equilibrium equation.

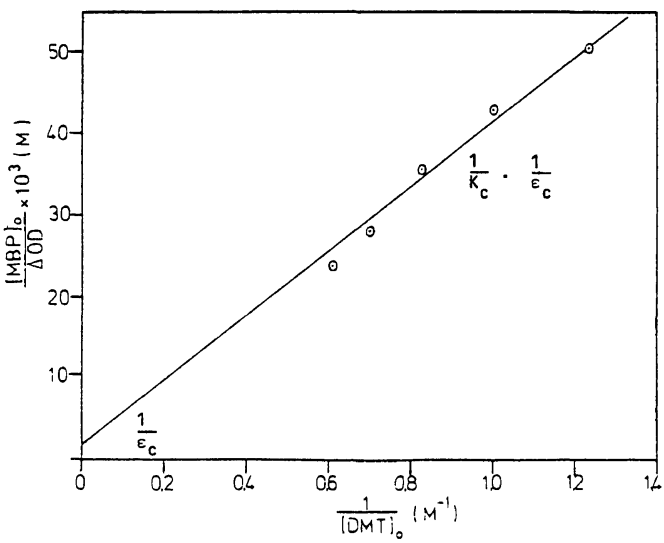

Figure 12. Benesi-Hildebrand plot for 4-methylbenzophenone and $N, N$-dimethyltoluidine.

that of PVB (Figure 10).

These absorption and emission spectra observations justify the use of crossed dyad concentration for calculating the complexation equilibrium constant instead of the overall D and A concentrations. $K$

Assuming the equilibrium Dyæ complex one obtains the equation $K=[\mathrm{C}] /\left([\mathrm{Dy}]_{0}-[\mathrm{C}]\right)$ were $[\mathrm{Dy}]_{0}$ is the initial dyad concentration and $[C]$ the concentration of complex at equilibrium. The equilibrium constant is in this case dimensionless. Since $[\mathrm{C}]=[\mathrm{OD}]_{\mathrm{c}} / \varepsilon_{\mathrm{c}},[\mathrm{OD}]_{\mathrm{c}}$ and $\varepsilon_{\mathrm{c}}$ being the optical density and extinction coefficient of the complex, by substitution one obtains the final equation $[O D]_{c}=\left\{\varepsilon_{c} /\right.$ $(1+(1 / K))\}[\mathrm{Dy}]_{0}$. $[\mathrm{Dy}]_{0}$ is the product of the crossed dyad probability $P_{(1.2)}{ }^{25}$ and the mean average 
concentrations of both $\mathrm{D}$ and $\mathrm{A}$ components, i.e.,

$$
\left([\mathrm{Dy}]_{0}=\left([\mathrm{A}]_{0}+[\mathrm{D}]_{0}\right) / 2\right) P_{(1.2)}
$$

Plotting $[\mathrm{OD}]_{\mathrm{c}}$ against $[\mathrm{Dy}]_{0}$, a slope equal to $\varepsilon_{\mathrm{c}} /$ $(1+(1 / K))=350$ is obtained (Figure 11). Assuming $K=1, \varepsilon_{\mathrm{c}}=700$ (at $340 \mathrm{~nm}$ ). For the model compounds MBP and DMT, on the basis of the classical Benesi-Hildebrand ${ }^{26}$ equation $\varepsilon_{\mathrm{c}}=400 \pm 100$ and $K_{\mathrm{c}}=0.07\left(\mathrm{in} \mathrm{mol}^{-1}\right.$ ) at $367 \mathrm{~nm}$ (Figure 12).

If one considers terpolymers VB, DAS, and methyl acrylate locally excited state benzophenone emission is clearly observed; difference spectra show nevertheless always the presence of excited state complexes as well. Even in a terpolymer co(VB8, DAS5, MA87) polymer, where the D and A groups are practically isolated from each other by the high MA content, and where the structural dyad probability is negligible, phosphorescence emission is still observed. The participation of remoted A and $\mathrm{D}$ groups to complex formation has therefore to be taken into account.

As pointed out above excited state complexation should be followed up by $\mathrm{H}$-exchange within the radical-ions pair, and formation of free radicals. It is their combination that results in crosslinking. It was therefore interesting to study the formation of radicals in a film of terpolymer (VB47, DAS14, $\mathrm{BuA39}$ ) in function of the time of irradiation, and their subsequent decay. EPR measurements have been carried out at $20^{\circ} \mathrm{C}$ and $79^{\circ} \mathrm{C}$, i.e., below and above the glass transition temperature of the terpolymer $\left(T_{\mathrm{g}} 64^{\circ} \mathrm{C}\right)$. The plots of the radical concentration according to a simple second order kinetics show two successive phases (Figure 13). The use of the integrated equation of Waite for diffusion controlled reaction, ${ }^{27-30}$ namely

$$
\frac{\frac{1}{C}-\frac{1}{C_{\mathrm{o}}}}{t}=4 \pi r_{0} D+8 r_{0}^{2} \sqrt{\frac{D}{t}}
$$

by plotting the left hand term against $1 / t^{1 / 2}$ permits to evaluate the characteristic parameters of the system, namely the radius of the kinetic cage $r$, the diffusion constant $D$ and the lifetime of the radicals in the cage. In this expression $C_{0}$ and $C$ are the concentration of the radical at time 0 and after decay time $t$ (Figure 14). The results are given in Table VIII.

Experiments carried out by incorporating 4hydroxy-2,2,6,6-tetramethylpiperidinoxy radicals

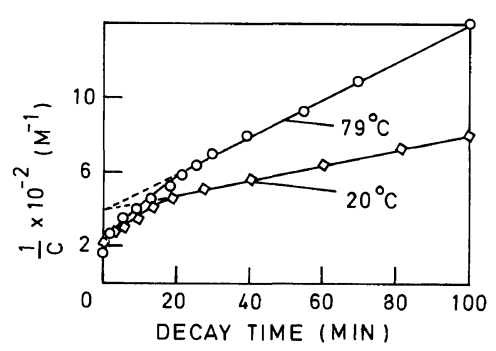

Figure 13. Radical decay with time. Second order kinetic plot.

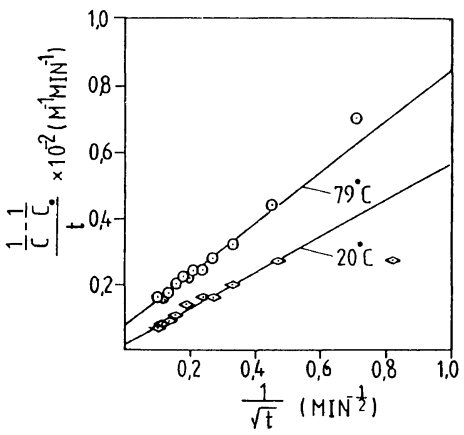

Figure 14. Radical decay with time following Waite's equation.

Table VIII. Kinetic parameters of radical decay in terpolymer (VB41, DAS14, BuA39)

\begin{tabular}{|c|c|c|}
\hline & $20^{\circ} \mathrm{C}$ & $79^{\circ} \mathrm{C}$ \\
\hline$k_{\mathrm{D}}$ in $\mathrm{mol} \mathrm{M}^{-1} \mathrm{~s}^{-1}$ & 0.03 & 0.13 \\
\hline$D$ in $\mathrm{cm}^{2}$ molecule $\mathrm{e}^{-1} \mathrm{~s}^{-1}$ & $8 \times 10^{-18}$ & $4.1 \times 10^{-12}$ \\
\hline$r_{0}$ in $\AA$ & 55 & 43 \\
\hline$\tau$ in $\mathrm{s}^{-1}$ & 120 & 14 \\
\hline
\end{tabular}
film ${ }^{\mathrm{a}}\left(T_{\mathrm{g}}=64^{\circ} \mathrm{C}\right)$

a $k_{\mathrm{D}}$, rate constant of diffusion.

(nitroxyl $1.2 \times 10^{-3} \mathrm{M}$ ) in the film permitted also to follow the rate of formation of radicals and their diffusion out of the cage by measuring the decrease of total radical concentration with the time of irradiation. Figure 15 represents the change above and below $T_{\mathrm{g}}$ at high intensity of irradiation. Again the importance of the physical state of the matrix is evident. Cage recombination of radicals produced in the film must be very important; it explains that the rate of cross-linking is apparently insensitive to 


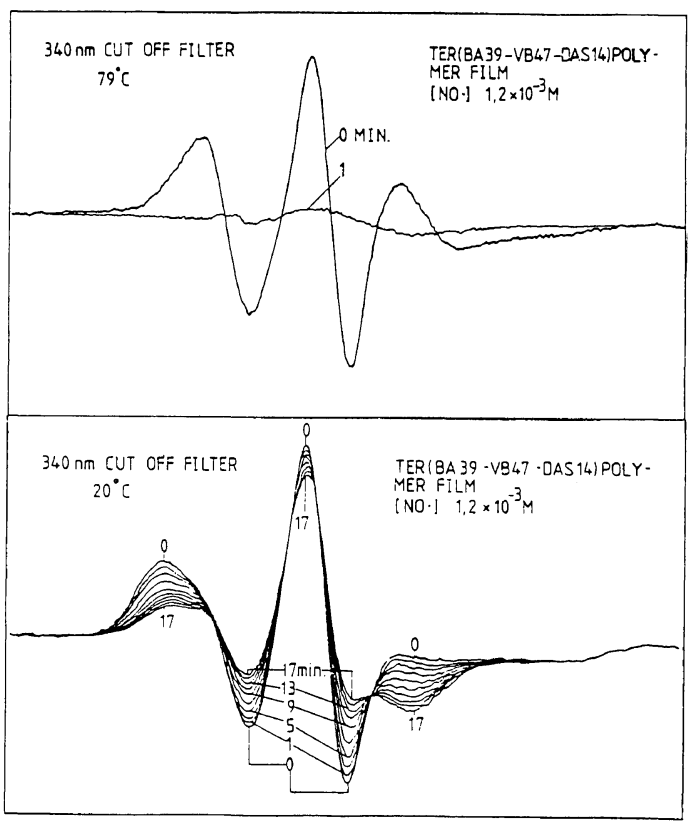

Figure 15. Change of total radical concentration in terpolymer in the presence of nitroxyl free radicals $\left(1.2 \times 10^{-3}\right.$ molar $)$ at 20 and $79^{\circ} \mathrm{C}$.

air oxygen, and in large limits independent of the film composition.

Acknowledgement. The author is indebted to his coworkers for their much appreciated collaboration, particularly Mr. T. Doi, Dr. T. J. Oh, drs. L. Raeymaekers, Dr. Schmitz-Smets, Dr. W. Van Broeckhoven. Financial support of the Ministry of Scientific Programmation, Belgium, is gratefully acknowledged.

\section{REFERENCES}

1. G. Delzenne, U. Laridon, and H. Peeters, Eur. Polym. J., 6, 933 (1970).

2. C. W. Wilkins, E. Reichmanis, and E. A. Chandross, J. Electrochem. Soc., 127, 2510, 2517 (1980).

3. M. Schmitz-Smets and G. Smets, Polym. Sci., in press.
4. G. Smets, Adv. Polym. Sci., 50, 18 (1983) and references therein.

5. J. Guillet in "Degradation and Stabilization of Polymers," G. Geuskens, Ed, Applied Science Publishers, London Ltd., 1975, p 181.

6. A. Ledwith, Pure Appl. Chem., 49, 437 (1977).

7. L. Raeymaekers, Ph. D. thesis K. U. Leuven in preparation.

8. G. M. Lukovin, S. Pshezhetsky, and G. A. Murtazaeva, Eur. Polym. J., 9, 559 (1973).

9. H. Van den Broeck, thesis K. U. Leuven, 1981.

10. T. St. Pierre and M. Geckle, Polym. Prepr. Am. Chem. Soc. Div., Polym. Chem., 22, 128 (1981).

11. E. Lanza, H. Berghmans, and G. Smets, J. Polym. Sci., Polym. Phys. Ed., 11, 95 (1973).

12. T. Doi, postgraduate fellow Asahi Glass K. U. Leuven, private communication.

13. E. P. 82810026.3 Ciba-Geigy Basel 22.1.82.

14. A. Ueda and S. Nagai, J. Polym. Sci., Polym. Chem. Ed., 22, 1611 (1984).

15. A. I. Prisyazhnyuk and S. S. Ivanchev, J. Org. Chem., U.S.S.R., 5, 1151 (1969).

16. A. I. Prisyazhnyuk and S. S. Ivanchev, Polym. Sci., U.S.S.R., 12, 514 (1970).

17. S. S. Ivanchev and Y. L. Zherebin, Polym. Sci., U.S.S.R., 16, 956 (1974); J. Org. Chem., U.S.S.R., 9, 1628 (1973).

18. Y. L. Zherebin, S. S. Ivanchev, and N. M. Domareva, Polym. Sci., U.S.S.R., 16, 1033 (1974).

19. S. S. Ivanchev, Polym. Sci., U.S.S.R., 20, 2157 (1978) and references therein.

20. W. Van Broeckhoven, Ph. D. thesis K. U. Leuven, 1982.

21. I. Piirma and L. P. Chou, J. Appl. Polym. Sci., 24, 2051 (1979).

22. C. Simionescu, K. G. Sik, E. Comatina, and S. Dumitriu, Eur. Polym. J., 20, 467 (1984).

23. G. J. Smets, Sabr Nal El Hamouly, and Tae J. Oh, Pure Appl. Chem., 56, 439 (1984).

24. Tae J. Oh, Ph. D. thesis K. U. Leuven June, 1984.

25. F. A. Bovey, "Chain Structure and Conformation of Macromolecules," Academic Press, New York, N. Y., 1982.

26. H. A. Benesi and J. H. Hildebrand, J. Am. Chem. Soc., 81, 6138 (1959).

27. P. J. Butyagin, Pure Appl. Chem., 30, 57 (1972).

28. G. Smets, G. Nijst, M. Schmitz-Smets, and A. Somers, J. Polym. Sci., Polym. Symp., 67, 83 (1980).

29. T. R. Waite, Phys. Rev., 107, 463 (1957).

30. T. R. Waite, J. Chem. Phys., 28, 103 (1958). 